\title{
Current diagnostic imaging of pheochromocytomas and implications for therapeutic strategy (Review)
}

\author{
FILIP ČTVRTLÍK ${ }^{1}$, PAVEL KORANDA ${ }^{2}$, JAN SCHOVÁNEK ${ }^{3}$, \\ JOZEF ŠKARDA ${ }^{4}$, IGOR HARTMANN ${ }^{5}$ and ZBYNĚK TÜDÖS ${ }^{1}$ \\ Departments of ${ }^{1}$ Radiology, ${ }^{2}$ Nuclear Medicine, ${ }^{3}$ Internal Medicine III-Nephrology, Rheumatology and Endocrinology, \\ ${ }^{4}$ Clinical and Molecular Pathology and ${ }^{5}$ Urology, University Hospital and Faculty of Medicine and Dentistry, \\ Palacky University, 77900 Olomouc, Czech Republic
}

Received August 8, 2017; Accepted January 3, 2018

DOI: $10.3892 /$ etm.2018.5871

\begin{abstract}
The topic of pheochromocytomas is becoming increasingly popular as a result of major advances in different medical fields, including laboratory diagnosis, genetics, therapy, and particularly in novel advances in imaging techniques. The present review article discusses current clinical, biochemical, genetic and histopathological aspects of the diagnosis of pheochromocytomas and planning of pre-surgical preparation and subsequent surgical treatment options. The main part of the paper is focused on the role of morphological imaging methods (primarily computed tomography and magnetic resonance imaging) and functional imaging (scintigraphy and positron emission tomography) in the diagnosis and staging of pheochromocytomas.
\end{abstract}

\section{Contents}

1. Introduction

2. Etiopathogenesis

3. Genetics

4. Clinical presentations

5. Biochemical tests

6. Imaging methods

7. Histopathology

8. Therapy

9. Conclusion

Correspondence to: Dr Zbyněk Tüdös, Department of Radiology, University Hospital and Faculty of Medicine and Dentistry, Palacky University, I.P. Pavlova 6, 77900 Olomouc, Czech Republic E-mail: zbynek.tudos@seznam.cz

Key words: pheochromocytoma, adrenal masses, incidentalomas, imaging, adrenalectomy

\section{Introduction}

Pheochromocytomas undoubtedly represent an interesting topic for specialists in fields as diverse as internal medicine, genetics, histopathology, radiology, urology, and anaesthesia. Correct and timely diagnosis of pheochromocytomas is crucial for patients' positive clinical outcome. The management and treatment of suspected pheochromocytomas usually starts with a biochemical investigation followed by morphological imaging, usually computed tomography (CT). In the vast majority of cases, positive CT findings together with biochemical tests provide sufficient evidence for the diagnosis of a pheochromocytoma.

The aim of this article is to review recent multidisciplinary advances in everyday diagnostic and therapeutic practice, with an emphasis on the role of imaging methods.

\section{Etiopathogenesis}

Pheochromocytomas are a rare type of neuroendocrine tumour originating from the chromaffin cells of the sympathoadrenal system with permanent or paroxysmal catecholamine hypersecretion $(1,2)$. The adrenal medulla is the tissue that is most frequently involved, but the location can also be extra-adrenal; such tumours are called paragangliomas and are divided into two groups. Sympathetic paragangliomas, mostly arising from the abdomen, share their clinical symptomatology with pheochromocytomas; on the contrary, parasympathetic paragangliomas, mostly located in the head and neck, could be locally invasive, but rarely produce catecholamines (1). The WHO published its latest classification criteria in $2017(3,4)$, as well as AJCC publishing the first staging system for pheochromocytomas and paragangliomas that takes into account the location of the tumour, size of the primary tumour, and hormone secretion $(5,6)$. Adrenal pheochromocytomas constitute $80-85 \%$ of cases, with paragangliomas making up 15-20\% of cases in the general population $(2,7)$. Unless specified otherwise in this review, the term 'pheochromocytoma' also refers to sympathetic paragangliomas. The estimated prevalence of pheochromocytomas is $1: 2,500$ to $1: 1,650$, with an annual incidence between 1,000 and 2,000 cases, including 100-200 pediatric patients and 100-200 with metastatic disease (8). 


\section{Genetics}

Approximately $40 \%$ of pheochromocytomas are of hereditary origin, the highest degree of heritability amongst any endocrine tumour type $(1,8)$. Knowledge of the specific genetic background is nowadays of increasing importance with regard to the clinical consequences (9-13). Currently, there are at least 12 different genetic syndromes, 15 well-known susceptibility genes, and an increasing number of potential disease-modifying genes (8). From the known syndromic presentations, the most common are syndromes of familial multiple endocrine neoplasia type 2A (MEN2A) or type 2B (MEN2B), neurofibromatosis type 1 (NF1), and von Hippel-Lindau syndrome type 2 (VHL 2). Furthermore, familial paraganglioma syndromes are associated with mutations in genetic encoding for the enzyme succinate dehydrogenase subunits A, B, C, and D (SDHA, SDHB, SDHC, and SDHD) (14-17). The association between recurrent, aggressive, and metastatic paragangliomas and the SDHB gene mutation is clinically important (18).

Data from the Comprehensive Molecular Characterization of Pheochromocytoma and Paraganglioma study proposed a molecular taxonomy of pheochromocytomas and paragangliomas which has the potential to personalize genetic and biochemical screening, imaging, follow-up, treatment, and prevention of the development of a tumour. Patients could be divided into three main disease clusters: i) pseudohypoxic, ii) Wnt-signalling, and iii) kinase-signalling $(8,19)$.

The latest Endocrine Society Clinical Practice Guideline on Pheochromocytoma and Paraganglioma recommends that all patients with pheochromocytomas should be engaged in shared decision making for genetic testing. A clinical feature-driven diagnostic algorithm was created to establish the priorities for specific genetic testing in pheochromocytoma patients with suspected germline mutations. Patients with paragangliomas should undergo testing for SDH mutations and patients with metastatic disease should undergo testing for SDHB mutations (7).

The number of susceptibility genes is increasing and their testing with traditional technologies is becoming laborious, and therefore the application of next-generation sequencing (NGS) technology might represent the near future for patients with those tumours. A Consensus Statement with specific recommendations for the use of diagnostic NGS was published recently (20).

\section{Clinical presentations}

Pheochromocytomas and paragangliomas typically present with symptoms of catecholamine excess. Most of the symptoms are non-specific, including headaches, palpitations, sweating, anxiety, nervousness, chest or abdominal pain, nausea, fatigue, dyspnea, dizziness, intolerance to heat, paresthesia/pain, blurred vision, constipation, or diarrhoea (9). The typical clinical manifestation of a pheochromocytoma is sustained or paroxysmal hypertension, and if the triad of headaches, palpitations, and sweating is accompanied by hypertension, a pheochromocytoma should be suspected. Other very common symptoms include orthostatic hypotension, pallor, flushing, fever, hyperglycemia, vomiting, and convulsions (9). Cardiovascular complications include hypertensive crises, sudden death, arrhythmias, myocardial infarction, heart failure resulting from cardiomyopathy (including tako-tsubo cardiomyopathy), aortic dissection, stroke, non-cardiac pulmonary oedema, and shock (21). Unrecognized and untreated pheochromocytomas can lead to devastating and even fatal consequences (22).

\section{Biochemical tests}

The gold standard for the detection of catecholamine hypersecretion is to measure plasma-free or urinary fractionated metanephrines $(7,22,23)$. Free plasma methoxytyramine measurements may be used, if the test is available, to detect a rare dopamine-producing tumour $(24,25)$.

Therefore optimal screening and follow-up should include the measurement of metanephrine, normetanephrine, methoxytyramine, and chromogranin A, to find one of four possible secretory profiles: Adrenergic, noradrenergic, dopaminergic, and silent. Catecholamine secretion reflects cell differentiation and can be used as a prognostic biomarker (8).

If the test results are ambiguous, the clonidine test may confirm the diagnosis; the test is also able to identify falsely positive catecholamine elevation (26). It should be noted that the standardized condition for the blood sampling must be followed and interfering medication should be avoided.

\section{Imaging methods}

The imaging modalities for pheochromocytomas can be either morphological (US, CT, and MRI) or molecular (scintigraphy and PET) or a combination of both-the fusion of morphological and molecular methods (SPECT/CT or PET/CT). Imaging is performed to determine the location of the tumour following clinical and biochemical examinations in clinically manifested pheochromocytomas. A different approach is used in adrenal mass discovered incidentally by imaging methods; in such a case clinical and biochemical tests follow imaging.

Morphological imaging. Anatomical imaging methods usually follow clinical suspicion and positive biochemical tests. Their role is to detect and locate pheochromocytomas.

The valuable general morphological features that help identify pheochromocytomas include size, consistency, and shape. The size may vary from 1 to $15 \mathrm{~cm}$ (27), or, rarely, even more. At the time of the diagnosis, the average size is approximately 4-6 cm (27-32). Smaller tumours usually consist of solid, relatively homogeneous tissue (Fig. 1). For larger tumours, the presence of greater or lesser central necrosis with a peripheral rim of tumour tissue is typical (Fig. 2). There is also a pure cystic form of pheochromocytoma.

The shape of a pheochromocytoma is usually spherical and the edges are relatively smooth.

The diverse morphological appearance of pheochromocytomas may well mimic other adrenal masses on CT and MRI scans (33). Differential diagnosis should aim to distinguish a pheochromocytoma from an adenoma, metastasis, or adrenal carcinoma.

Ultrasonography. Abdominal sonography may incidentally detect an adrenal mass, especially on the right side because 

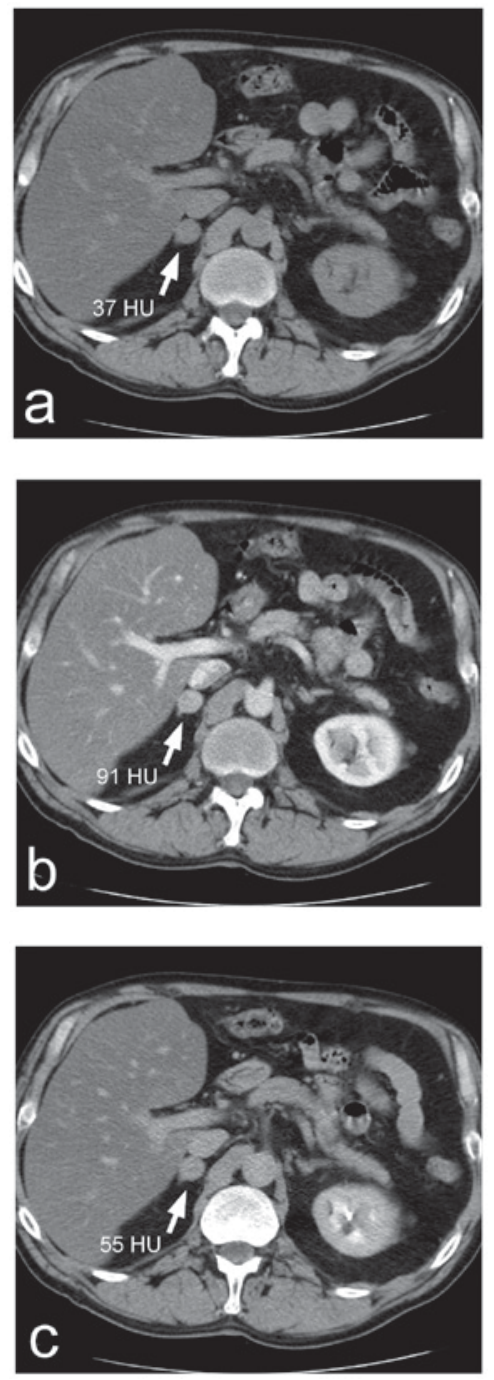

Figure 1. Small adrenal pheochromocytoma on the right side (arrows): (a) non-enhanced CT scan in the axial plane, (b) contrast-enhanced CT scans (venous phase) in the axial plane, (c) contrast-enhanced CT scan (delayed phase $10 \mathrm{~min}$ after) in the axial plane. The wash-out rate calculation is $61 \%$, which fulfils the threshold for an adenoma. CT, computed tomography; HU, Hounsfield units.

of the acoustic window of the liver. Otherwise, the role of ultrasound in the management of pheochromocytomas is limited.

Computed tomography $(C T)$. CT is the most common imaging method used in the diagnosis of pheochromocytomas. Compared to MRI, it is more widely available, less expensive, and offers better spatial resolution. The main disadvantage of $\mathrm{CT}$ is ionizing radiation. CT scans can reveal adrenal pheochromocytomas larger than $5-10 \mathrm{~mm}$ with sensitivity $>95 \%$ (34).

The differentiation of a pheochromocytoma from a lipid-rich adenoma by means of the unenhanced attenuation value in Hounsfield units (HU) is straightforward, since the attenuation in pheochromocytomas is always higher than $10 \mathrm{HU}$ (Fig. 1a) (29). This fact results from an absence of intra-cytoplasmic lipids within pheochromocytoma tumours, which also applies to metastases and adrenocortical carcinomas (35). If the average unenhanced attenuation value of a lesion exceeds $10 \mathrm{HU}$, it is possible to perform histogram
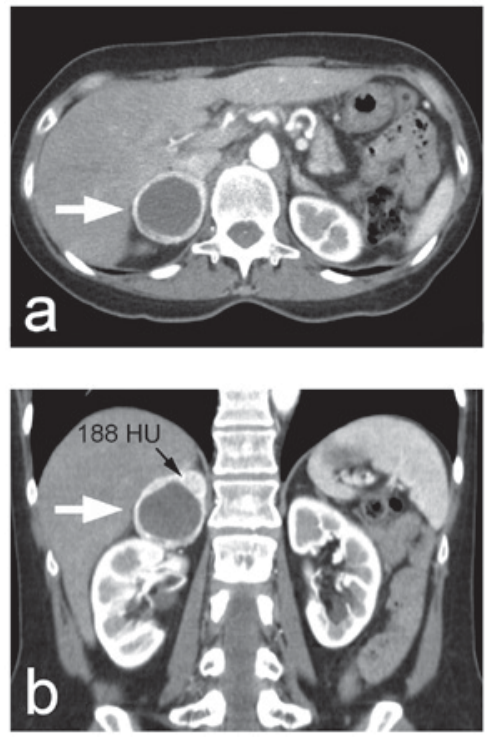

Figure 2. Adrenal pheochromocytoma on the right side (white arrows): (a) contrast-enhanced CT scans (arterial phase) in the axial plane, (b) contrast-enhanced CT scan in the coronal plane. The tumour has a regular spherical shape, smooth margin, and central necrosis. Contrast-enhanced attenuation of the peripheral rim in arterial phase reached more than $180 \mathrm{HU}$ (black arrow). CT, computed tomography; HU, Hounsfield units

analysis of the unenhanced CT image; if there are $10 \%$ or more negative pixels in the histogram, an adenoma can be confirmed as it is thus distinguished from other adrenal lesions, including pheochromocytomas (36). Currently, more advanced methods of histogram evaluation (also called ' $\mathrm{CT}$ texture analysis') have been introduced (37); according to a recent paper, pheochromocytomas had a significantly higher mean grey-level intensity, entropy, and mean of positive pixels, but lower skewness and kurtosis in unenhanced images compared to lipid-poor adenomas (32).

After the administration of an iodine contrast medium, pheochromocytomas usually display pronounced enhancement, often more than $130 \mathrm{HU}$. In smaller solid lesions, the enhancement is relatively homogeneous (Fig. 1b), while in larger lesions the character of the enhancement is more or less heterogeneous; something that is very typical of pheochromocytomas with central necrosis is the pronounced enhancement of the peripheral rim of the viable tumour tissue (Fig. 2). Although strong enhancement occurs in most pheochromocytomas, it cannot be considered specific, since there is significant overlap of contrast enhancement with other types of adrenal lesions (29); only a single article has reported significant differences in the enhancement of adenomas and pheochromocytomas (38).

The targeted adrenal CT protocol usually includes late-enhancement scans (i.e., 7-15 min after the application of a contrast medium), which allows the measurement of the absolute and relative decreases in post-contrast attenuation, which reflect the rate of contrast medium washout. Adenomas are believed to express rapid washout compared to the slower washout of pheochromocytomas (39-42). However, according to some papers, up to one third of pheochromocytomas overlap with adenomas in terms of their relative or absolute washout rate (Fig. 1a-c) (30,31). Furthermore, washout rates are unable 

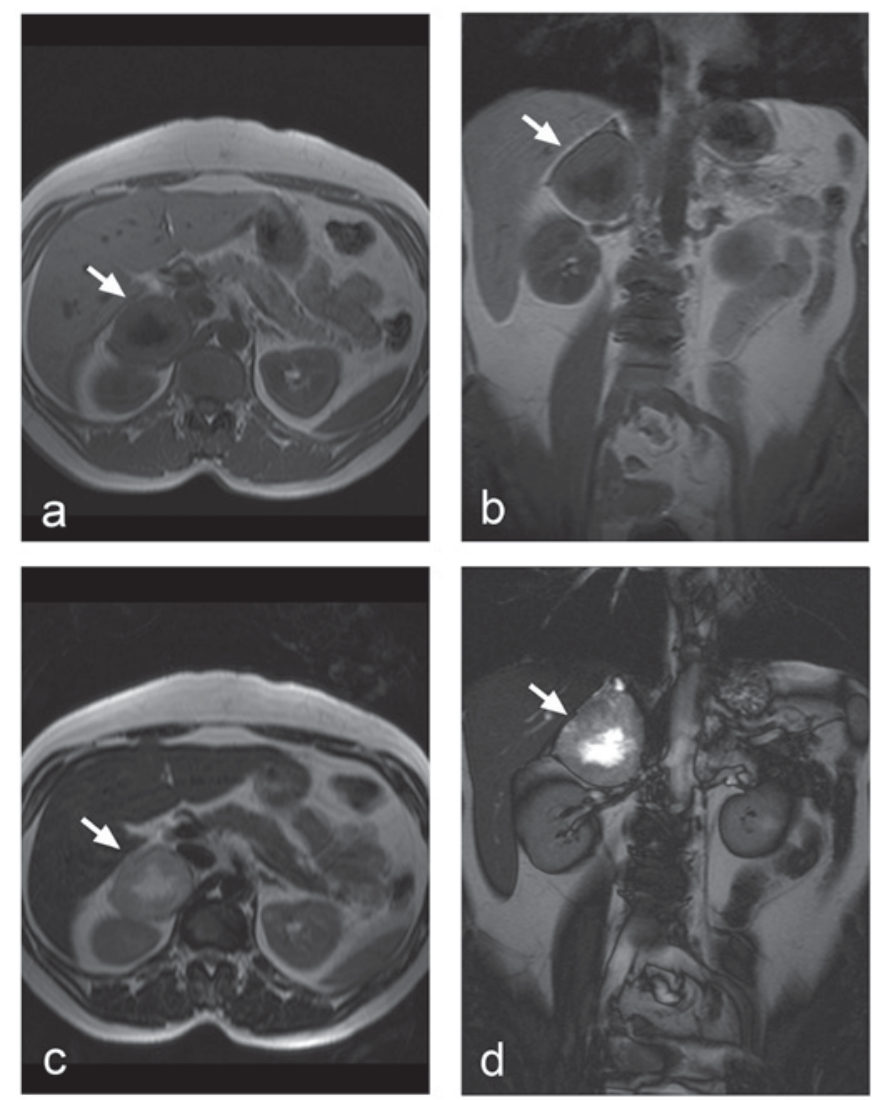

Figure 3. Adrenal pheochromocytoma on the right side (arrows): (a) $\mathrm{T}_{1}$-weighted spoiled gradient echo in the axial plane, (b) $\mathrm{T}_{1}$-weighted spoiled gradient echo in the coronal plane, (c) $\mathrm{T}_{2}$-weighted turbo spin echo in the axial plane, (d) True FISP in the coronal plane. $T_{2}$-weighted image showing typical high signal intensity in the central necrotic part, which appears hypointense in $\mathrm{T}_{1}$-weighted images.

to distinguish pheochromocytomas from adrenal carcinomas or metastases (41).

Studies with a non-ionic contrast medium (Iohexol) failed to confirm the widespread opinion that the intravenous administration of an iodinated contrast medium can lead to increased secretion of catecholamines from pheochromocytomas or may even lead to a hypertensive crisis (43). This result was replicated by another study providing evidence that the administration of iodinated non-ionic contrast media in patients with a suspected or known pheochromocytoma is safe, and the administration of $\alpha$-adrenergic receptor blockers before the administration of the contrast medium is not necessary (44).

Magnetic resonance imaging. MRI is not a first-choice imaging tool because of its lower spatial resolution, lower logistical availability, higher price, and stricter safety regulations. But it benefits from being free of ionizing radiation and therefore suitable e.g., in cases of pregnant women or children or in patients with adverse reactions to an iodinated contrast medium.

The appearance of pheochromocytomas in $\mathrm{T}_{1^{-}}$and $\mathrm{T}_{2}$-weighted images depends on whether the tumour is solid, cystic, or haemorrhagic/necrotic. Cystic tumours display high signal intensity in $\mathrm{T}_{2}$-weighted images. A similar picture is
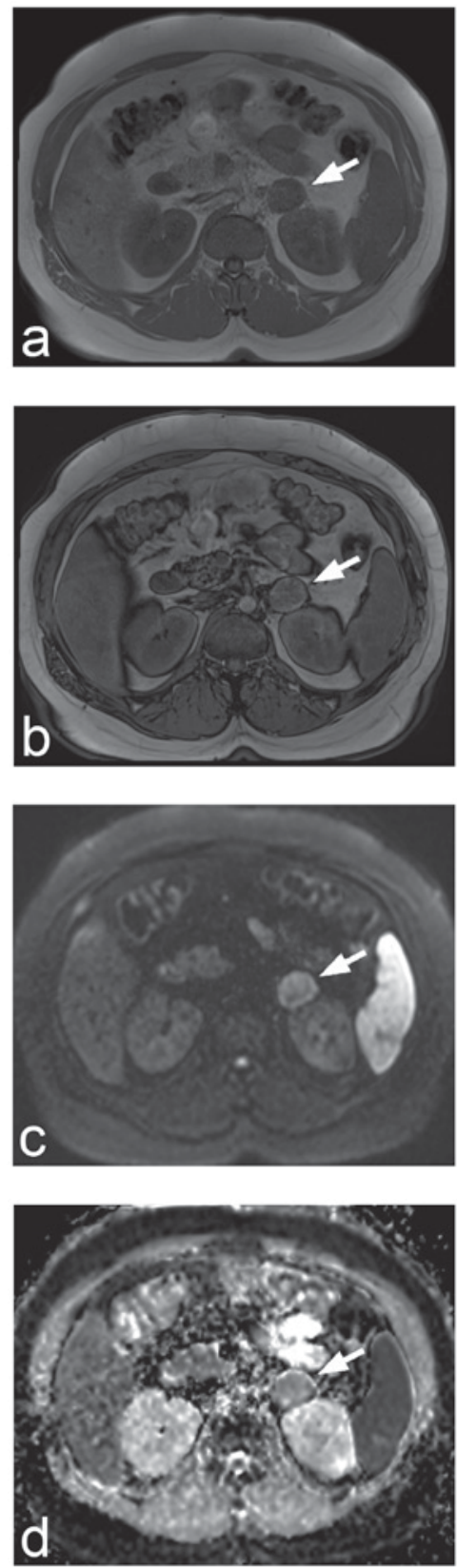

Figure 4. MRI of adrenal pheochromocytoma on the right side (arrows): (a) axial $\mathrm{T}_{1}$-weighted 'in-phase' image, (b) axial $\mathrm{T}_{1}$-weighted 'out-of-phase' image, (c) axial diffusion-weighted image ( $b=800$ ), (d) axial ADC map. The lesion shows no decrease in the signal in the 'out-of-phase' image. Restricted diffusion is present on the ADC map. ADC, apparent diffusion coefficient.

seen in pheochromocytomas with central necrosis (Fig. 3), but the classical pattern of a T2 hyperintense pheochromocytoma is relatively uncommon (27). The signal intensity of the haemorrhage in $\mathrm{T}_{1^{-}}$and $\mathrm{T}_{2}$-weighted images could vary considerably, because the signal changes over the time since it depends on the age of the haematoma. However, generally speaking, the signal intensity of blood is predominantly high in $\mathrm{T}_{1}$-weighted images. Smaller solid pheochromocytomas could be distinguished from adrenal adenomas by means of chemical shift imaging, because unlike adenomas, pheochromocytomas contain no intracellular lipids, and thus they show no signal changes in out-of-phase and in-phase images (Fig. 4a and b) (45). 


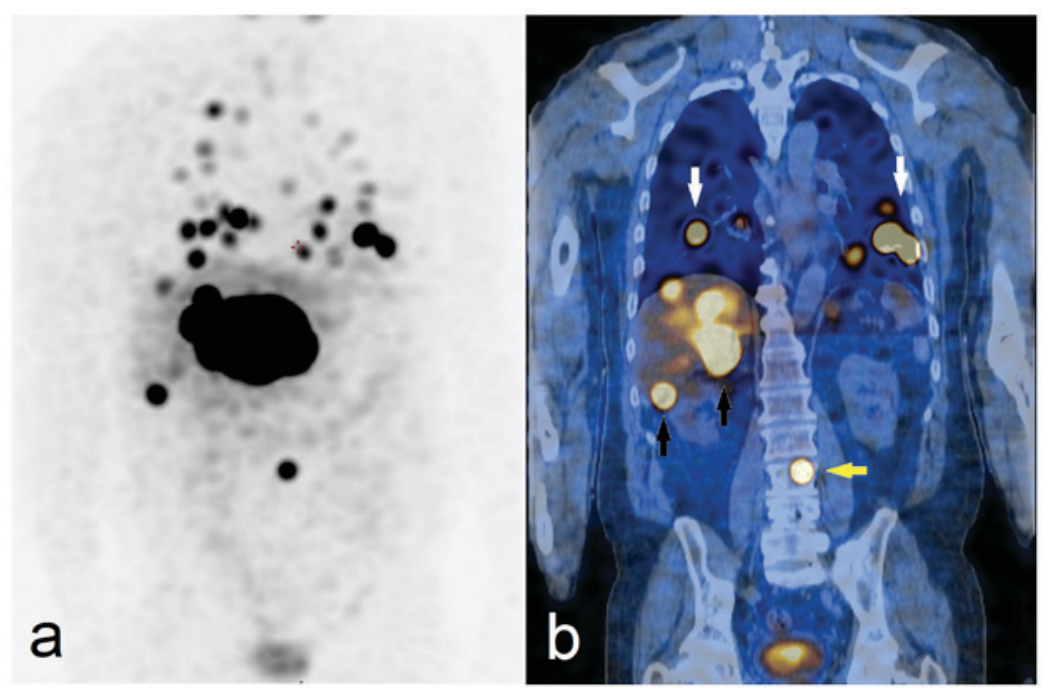

Figure 5. ${ }^{123}$ I-MIBG SPECT/CT study: (a) maximum-intensity projection, (b) coronal slice. Re-staging examination reveals the metastatic spread of malignant pheochromocytoma into the lungs (white arrows), liver (black arrows), and vertebra L3 (yellow arrow). The patient subsequently underwent ${ }^{131} \mathrm{I}-\mathrm{MIBG}$ therapy. I-MIBG, I-metaiodobenzylguanidine.

Another option of MRI is diffusion-weighted imaging (DWI) and calculation of apparent diffusion coefficient (ADC) maps (Fig. 4c and d). Significantly higher ACD values were observed in pheochromocytomas compared to adenomas and metastases (46). ADC histogram analysis was also applied and revealed significant differences between pheochromocytomas and adenomas (47). ADC values might also help to distinguish benign from malignant pheochromocytomas (48).

MR spectroscopy of pheochromocytomas has been studied but is not routinely used $(49,50)$.

Although the use of paramagnetic contrast agents is rarely necessary, strong post-contrast enhancement of pheochromocytomas is similar to contrast-enhanced CT (51).

Paramagnetic contrast agents used in MRI do not lead to the hypersecretion of catecholamines (52).

Molecular imaging in the detection of pheochromocytomas. After the morphological imaging studies have been obtained, the functional imaging modality could be utilized to confirm the source of the increased production of catecholamines. For most of the cases one of the following methods is employed- ${ }^{123}$ I-MIBG scintigraphy, ${ }^{18} \mathrm{~F}-\mathrm{FDG}$, or ${ }^{18} \mathrm{~F}$-DOPA $\mathrm{PET} / \mathrm{CT}$ and somatostatin receptor imaging. The selection of the functional modality could be based on knowledge of the patient's genetic background, as recommended by the European Association of Nuclear Medicine (53).

${ }^{123} I-M I B G$ scintigraphy. For a long time, radioactive iodine-labelled ${ }^{123}$ I-metaiodobenzylguanidine ( $\left.{ }^{123} \mathrm{I}-\mathrm{MIBG}\right)$ has been used to reveal pheochromocytomas. MIBG is a guanethidine precursor and its structure resembles that of norepinephrine. Following intravenous application, it is transported by the reuptake mechanism into presynaptic adrenergic neuron cells, where it accumulates in catecholamine secretory granules through the adenosine triphosphate system (ATPase-dependent proton pump). The scintigraphic examination uses the intravenous application of ${ }^{123}$ I-MIBG tracer. The sensitivity of ${ }^{123}$ I-MIBG ranges between 85 and $88 \%$ for pheochromocytomas and between 56 and $75 \%$ for paragangliomas, whereas its specificity ranges from 70 to $100 \%$ and 84 to $100 \%$, respectively. Its sensitivity for metastatic pheochromocytomas is between 56 and $83 \%$, whereas for recurrent disease it is $\sim 75 \%$ (7).

Physiological MIBG uptake occurs in the salivary glands, the heart, the liver, and the spleen. Slightly elevated accumulation is also seen in the thyroid gland. Because of the renal excretion of the tracers, radioactivity is observed in the kidneys and the urinary bladder. The varying level of accumulation can also be observed in the nasal mucosa, neck muscles, lungs, and intestine. Medication which can prevent MIBG from accumulating in tumours (e.g., insulin, reserpine, amphetamine, calcium channel blockers, sympathomimetics) should be discontinued before the examination (54).

Pheochromocytomas appear on scintigrams as focal increased concentrations of radioactivity in the adrenal medulla but also in ectopic adrenergic tissue or metastases (Fig. 5). Paragangliomas can easily be missed on CT and MRI scans.

The advantages of ${ }^{123} \mathrm{I}-\mathrm{MIBG}$ are high-quality examination with less exposure to radiation and, compared to the later methods, its wide availability and relatively low cost.

Nowadays the ${ }^{123}$ I-MIBG examination is mostly recommended for patients with metastatic paragangliomas detected by other imaging modalities, when radiotherapy using ${ }^{131}$ I-MIBG is planned. Occasionally, it is used in some patients with an increased risk of metastatic disease because of the large size of the primary tumour or extra-adrenal, multifocal (except paragangliomas of the skull base and neck), or recurrent disease (7).

Somatostatin receptor scintigraphy. Another option in the visualization of pheochromocytomas is the detection of somatostatin receptors, whose concentration is increased in neuroendocrine tumours, including pheochromocytomas (Fig. 6). This imaging method uses radionuclide-labelled peptides, specifically somatostatin analogues ( ${ }^{111} \mathrm{In}$-pentetreotide, ${ }^{99 \mathrm{~m} T c-H Y N I C-T O C) . ~ S o m a t o s t a t i n ~}$ 

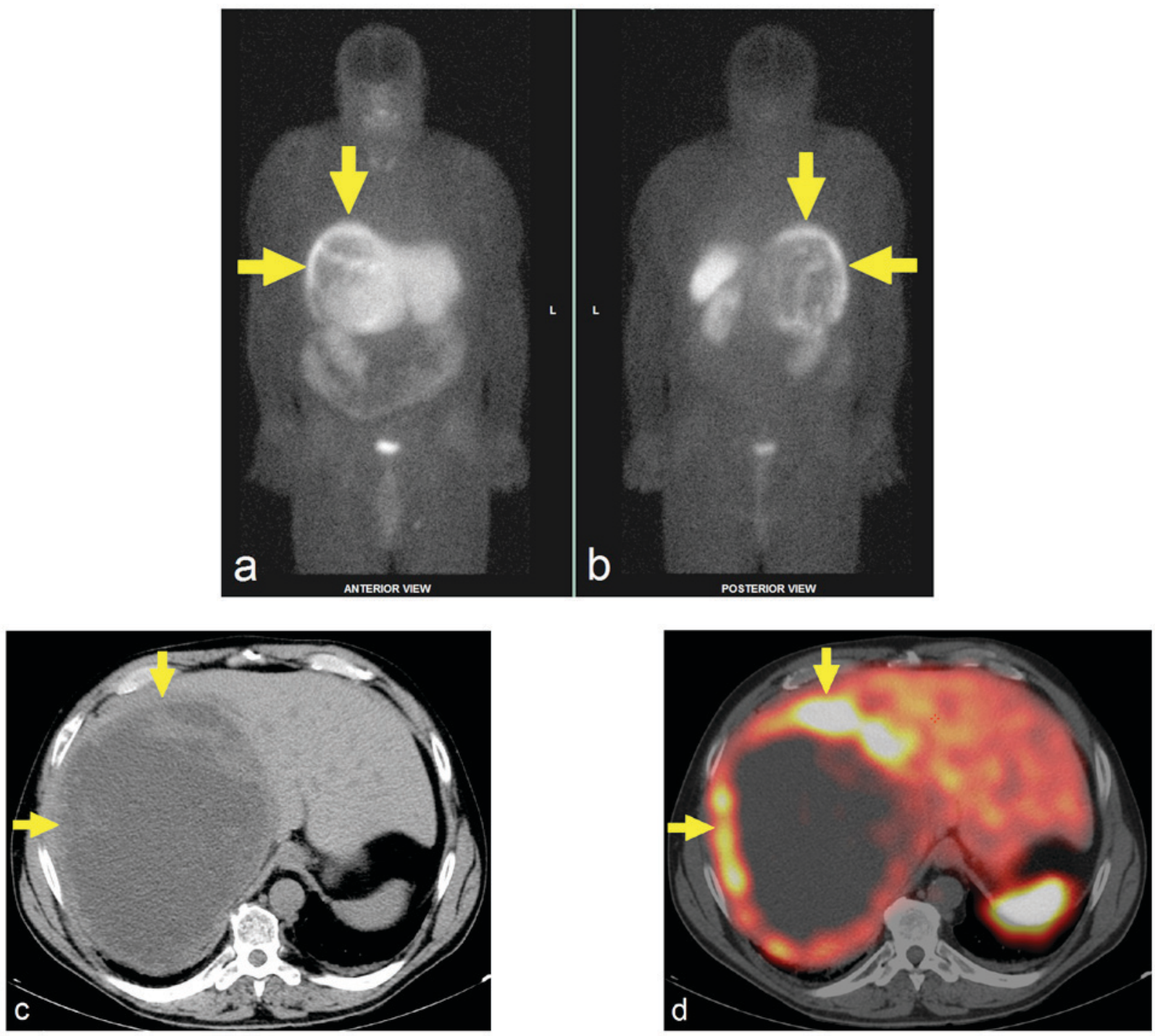

Figure $6 .{ }^{99 \mathrm{~m}} \mathrm{Tc}-\mathrm{HYNIC}-\mathrm{TOC}$ scintigraphy in a patient with atypical giant paraganglioma in: (a) Anterior and (b) posterior whole-body scintigrams, (c) axial CT scan, (d) axial SPECT/CT fusion. The examination confirmed the expression of somatostatin receptors in peripheral solid areas of the large tumour (arrows). $\mathrm{CT}$, computed tomography.

receptor imaging is mainly used in paragangliomas because of the relatively high physiological uptake of the radiopharmaceutical in the kidneys. This method is not recommended for hereditary tumours.

PET/CT. In most published examination schemes PET/CT with corresponding tracers is the preferred method for the detection of pheochromocytomas and paragangliomas and further wide use of this method can be expected. The most commonly used radiopharmaceuticals in this PET scanning are ${ }^{18} \mathrm{~F}-3$, 4-dihydroxyphenylalanine $\left({ }^{18} \mathrm{~F}\right.$-DOPA) and ${ }^{18} \mathrm{~F}$-fluorodeoxyglucose $\left({ }^{18} \mathrm{~F}-\mathrm{FDG}\right)$; the selection of the tracer is based on localization of the tumour and its genetic background $(7,53)$.

The advantage of ${ }^{18} \mathrm{~F}$-DOPA imaging is the lack of significant uptake in the normal adrenal medulla. The efficiency of ${ }^{18} \mathrm{~F}$-DOPA imaging of paragangliomas depends on the localization of the tumour and genetic status. ${ }^{18} \mathrm{~F}-\mathrm{DOPA}$ $\mathrm{PET} / \mathrm{CT}$ is an excellent diagnostic tool for head and neck paragangliomas, but its sensitivity can be lower in retroperitoneal paragangliomas (55). In metastatic disease the ${ }^{18} \mathrm{~F}-\mathrm{DOPA}$ PET detection rate of the lesions is higher in SDHB-negative patients than in SDHB-positive ones (56).

The visualization of paragangliomas using ${ }^{18} \mathrm{~F}-\mathrm{FDG}$ PET/CT is influenced by the degree of tissue differentiation, localization of the tumour, and genetic status (53). Increased ${ }^{18} \mathrm{~F}-\mathrm{FDG}$ uptake is a usual finding in pheochromocytomas, but the intensity of this uptake is variable. The sensitivity of ${ }^{18} \mathrm{FDG}$ PET/CT in the detection of pheochromocytomas is high, but unfortunately, its specificity is lower. In metastatic disease the ${ }^{18} \mathrm{~F}$-FDG PET/CT detection rate of the lesions is higher in SDHB-positive patients (Fig. 7) (contrary to ${ }^{18} \mathrm{~F}$-DOPA PET) (57). In patients with known metastatic pheochromocytomas, ${ }^{18} \mathrm{FDG} \mathrm{PET} / \mathrm{CT}$ is preferred over ${ }^{123}$ I-MIBG. ${ }^{123}$ I-MIBG is performed in this group of patients when treatment with ${ }^{131}$ I-MIBG is being considered (7).

${ }^{18} \mathrm{~F}$-fluorodopamine $\left({ }^{18} \mathrm{~F}\right.$-FDA $)$ and ${ }^{68} \mathrm{Ga}$-DOTA-peptides that specifically bind to somatostatin receptors are experimental PET tracers that have been successfully used in clinical studies (39). ${ }^{68} \mathrm{Ga}$-DOTA-peptides seem to represent the near 

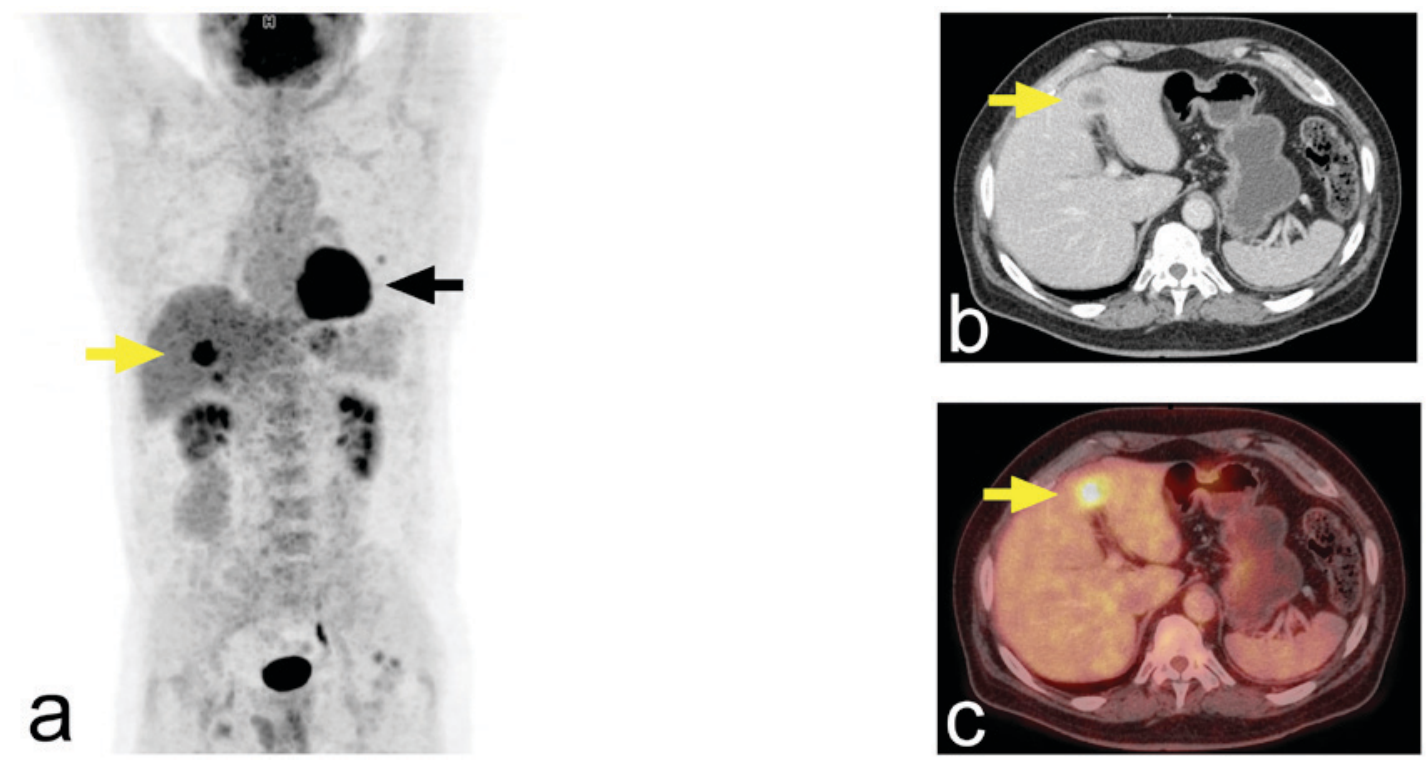

Figure 7. ${ }^{18}$ F-FDG PET/CT in SDHB-positive patient; (a) maximum-intensity projection, (b) axial CT slice, (c) fused axial ${ }^{18}$ F-FDG PET/CT image. The finding reveals the metastatic spread of malignant pheochromocytoma into the liver (yellow arrows) and the left lung (black arrow). ${ }^{18} \mathrm{~F}-\mathrm{FDG},{ }^{18} \mathrm{~F}$-fluorodeoxyglucose.

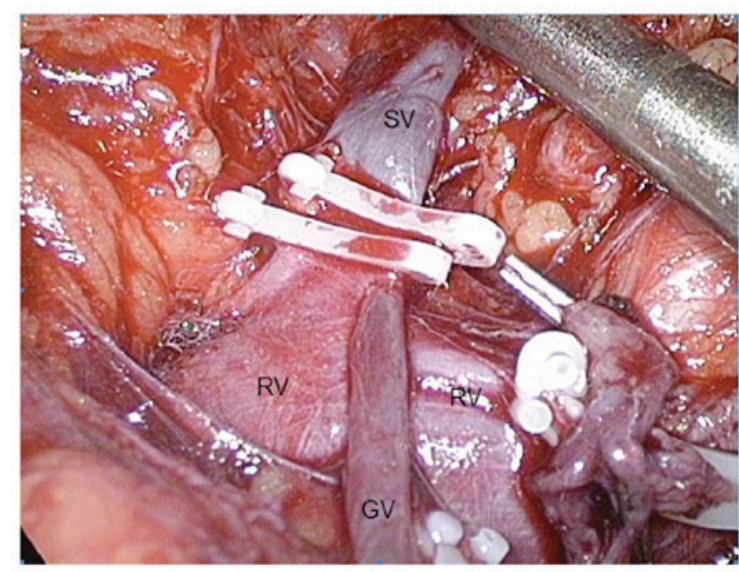

Figure 8. Photograph of a laparoscopic adrenalectomy: exposed left RV and $\mathrm{SV}$, clips placed on the suprarenal vein before attempting further manipulation of the pheochromocytoma. Incidental finding of an anomalous left GV draining into the left suprarenal vein. RV, renal vein; SV, suprarenal vein, $\mathrm{GV}$, gonadal vein.

future of the molecular imaging of pheochromocytomas. Their superiority in the localization of sporadic metastatic pheochromocytomas compared to all other functional and anatomical imaging modalities has been demonstrated (58-60).

Molecular imaging-tailoring of the diagnostic strategy according to guidelines $(7,53)$. Sporadic pheochromocytomas-the sensitivity of ${ }^{123} \mathrm{I}-\mathrm{MIBG}$ is similar to the case of PET imaging and superior to somatostatin imaging.

Head and neck paragangliomas-the most sensitive method is ${ }^{18} \mathrm{~F}$-DOPA PET/CT, but according to new studies imaging using ${ }^{68} \mathrm{Ga}$ labelled somatostatin analogues achieves similar results. The usage of ${ }^{18} \mathrm{FDG}$ PET/CT is beneficial in SDHx-related head and neck paragangliomas.

Retroperitoneal paragangliomas-the sensitivity of ${ }^{18} \mathrm{~F}$-DOPA PET/CT is higher than ${ }^{123} \mathrm{I}-\mathrm{MIBG}$ scintigraphy, and ${ }^{18} \mathrm{~F}$-FDOPA PET/CT is more specific than ${ }^{18} \mathrm{FDG} \mathrm{PET} / \mathrm{CT}$.
High sensitivity is exhibited by ${ }^{18}$ FDG PET/CT in SDHx- and VHL-related sympathetic paragangliomas.

Metastatic pheochromocytomas and paragangliomas${ }^{18} \mathrm{~F}-\mathrm{FDG}$ PET/CT is the preferred method in SDHB-related patients and the usage of ${ }^{18} \mathrm{~F}-\mathrm{FDOPA} \mathrm{PET} / \mathrm{CT}$ can be advantageous in the absence of SDHB mutations; in patients with unknown genetic status ${ }^{18} \mathrm{~F}-\mathrm{FDG}$ PET/CT should be used, optionally in combination with ${ }^{18} \mathrm{~F}$-FDOPA PET/CT or somatostatin receptor imaging. ${ }^{123} \mathrm{I}-\mathrm{MIBG}$ allows the appropriateness of radiotherapy to be assessed using ${ }^{131} \mathrm{I}-\mathrm{MIBG}$.

\section{Histopathology}

An important aspect of the clinical management of pheochromocytomas is the distinction between benign and malignant variants. In most cases, it is impossible to predict the biological properties of pheochromocytomas by imaging methods alone. Malignant variants can be reliably identified with imaging methods alone only in the presence of distant metastases.

Pheochromocytomas are tumours of the sympathochromaffin system. The histological diagnosis is straightforward thanks to the characteristic morphological pattern. What is not easy, however, is the prediction of their biological behaviour on the basis of histological criteria alone.

Histological signs of potential malignancy include a diffuse infiltrative growth, vascular and capsular invasion, tumour necrosis, increased mitotic activity, cellular polymorphism, and high proliferative activity as shown by immunohistochemistry. The histological evaluation must be comprehensive and must include immunohistochemical assessment of proliferative activity. If $\mathrm{Ki} 67>3 \%$ it is considered a useful parameter for predicting malignant potential (61).

Pheochromocytoma of the Adrenal gland Scaled Score (PASS) $<4$ had benign behaviour and all malignant cases had PASS $\geq 6$. A PASS score between 4 and 6 needs long-term follow-up. Some recent studies state that the values are $<4$ for benign tumours and $\geq 6$ for malignant tumours, whereas 
a value between 4 and 6 suggests an intermediate risk (62). A study performed on 100 cases stated that PASS can be used to separate tumours with the potential for biologically aggressive behaviour (PASS $\geq 4$ ) from those that behave in a benign fashion (PASS <4) (63).

In another study conducted on 11 patients, it was found that a PASS score $\geq 4$ identifies malignant pheochromocytomas with a sensitivity of $50 \%$ and specificity of $45 \%$. On the basis of this study it was suggested that PASS helps to reserve the more aggressive treatment and narrow the follow-up for potentially malignant tumours (64). It is known that the size and weight of the pheochromocytomas are directly related to PASS and malignancy (65).

Malignant pheochromocytomas and adrenocortical carcinomas can easily be mistaken for one another (66), which often leads to clinically significant consequences for the patient. Therefore, long periods of follow-up are necessary for patients following the surgical excision of pheochromocytomas (67). The average five-year survival rate for malignant pheochromocytomas ranges from 34 to $60 \%$ (9).

\section{Therapy}

Surgical removal of the tumour is currently the only treatment.

Preoperative management. The risk of catecholamine hypersecretion is significantly increased by biopsy. Therefore, needle biopsy should be avoided in clinically suspected pheochromocytomans and surgery should be performed directly $(68,69)$.

Preoperative pharmacological management of the pheochromocytoma is always needed to reduce the risk of perioperative complications. Pharmacological preparation of the patient significantly reduces the risk of perioperative mortality (70,71). Crucially, the patient should have an alpha-blocker administered for at least 14 days prior to surgery to reduce the risk of vasoconstriction. A beta-blocker can be administered prior to surgery as well to prevent tachycardia, if necessary. The administration of beta-blockers must not begin prior to alpha-blockade because of the risk of severe hypertension. An experienced anaesthesiologist should be present during the surgery to reduce the risk of possible circulatory complications.

Surgical technique. The surgical method of choice in the treatment of pheochromocytomas is laparoscopic adrenalectomy, performed via the trans- or retroperitoneal approach. The retroperitoneal approach is particularly suitable for the right adrenalectomy.

The rule of thumb for preventing complications during the resection of pheochromocytomas is to perform an early occlusion of the vein draining the adrenal medulla (known as the vena centralis), flowing into the renal vein on the left side (Fig. 8) and into the inferior vena cava on the right side. This is to minimize the secretion of catecholamines into the circulation during manipulation of the gland. Some well-established advantages of the laparoscopic approach include lower blood loss, less need for narcotics, a shorter hospital stay, and a more favourable cosmetic effect. The previous assumption that the intra-abdominal insufflation of carbon dioxide may induce hypertension has been refuted.
Open adrenalectomy is currently indicated only in tumours with signs of invasion into the surrounding structures or in the presence of a thrombus. The open approach is also preferred in tumours larger than 8-12 cm (72) and in the event of paraganglioma (7). In cases of a bilateral pheochromocytoma, e.g., in patients with VHL syndrome or MEN2A, partial adrenalectomy can be performed at least on one side to preserve the secretion of adrenal hormones.

In the long-term prognosis of patients after surgery is excellent; however, hypertension persists in almost $50 \%$ of cases (9).

\section{Conclusion}

Pheochromocytomas present important and interesting clinical features. Their management requires the cooperation and long-standing experience of several specialists. Timely and correct diagnosis of this condition is essential for the positive clinical outcomes of patients. In most cases, correct interpretation of the abdominal CT scan together with positive biochemical findings provides sufficient evidence for diagnosis and helps guide subsequent therapeutic decisions.

\section{Acknowledgments}

The present study was supported by the Ministry of Health of the Czech Republic (grant no. 17-31847A) and the Ministry of Health, Czech Republic-conceptual development of research organization (FNOL, 00098892).

\section{References}

1. Dahia PL: Pheochromocytoma and paraganglioma pathogenesis: Learning from genetic heterogeneity. Nat Rev Cancer 14: 108-119, 2014.

2. Lenders JW, Eisenhofer G, Mannelli M and Pacak K: Phaeochromocytoma. Lancet 366: 665-675, 2005.

3. Lam AK: Update on adrenal tumours in 2017 world health organization (WHO) of endocrine tumours. Endocr Pathol 28: 213-227, 2017.

4. Lloyd RV, Osamura RY, Klöppel G and Rosai J: WHO Classification of Tumours of Endocrine Organs. 4th edition. IACR, Lyon, 2017.

5. Roman-Gonzalez A and Jimenez C: Malignant pheochromocytoma-paraganglioma: Pathogenesis, TNM staging and current clinical trials. Curr Opin Endocrinol Diabetes Obes 24: 174-183, 2017.

6. Amin B, Edge S and Greene F: AJCC cancer staging manual. Springer, New York, 2017.

7. Lenders JW, Duh QY, Eisenhofer G, Gimenez-Roqueplo AP, Grebe SK, Murad MH, Naruse M, Pacak K and Young WF Jr; Endocrine Society: Pheochromocytoma and paraganglioma: An endocrine society clinical practice guideline. J Clin Endocrinol Metab 99: 1915-1942, 2014.

8. Crona J, Taïeb D and Pacak K: New perspectives on pheochromocytoma and paraganglioma: Towards a molecular classification. Endocr Rev 38: 489-515, 2017.

9. Pacak K and Del Rivero J: Pheochromocytoma (Updated June 10, 2013). In: Endotext. De Groot LJ, Chrousos G, Dungan K, Feingold KR, Grossman A, Hershman JM, Koch C, Korbonits M, McLachlan R, New M, et al (eds): MDText. com, Inc., South Dartmouth, MA, 2000.

10. Neumann HP, Bausch B, McWhinney SR, Bender BU, Gimm O, Franke G, Schipper J, Klisch J, Altehoefer C, Zerres K, et al: Germ-line mutations in nonsyndromic pheochromocytoma. N Engl J Med 346: 1459-1466, 2002.

11. Pacak K and Wimalawansa SJ: Pheochromocytoma and paraganglioma. Endocr Pract 21: 406-412, 2015. 
12. Qin Y, Yao L, King EE, Buddavarapu K, Lenci RE, Chocron ES, Lechleiter JD, Sass M, Aronin N, Schiavi F, et al: Germline mutations in TMEM127 confer susceptibility to pheochromocytoma. Nat Genet 42: 229-233, 2010

13. Tsirlin A, Oo Y, Sharma R, Kansara A, Gliwa A and Banerji MA: Pheochromocytoma: A review. Maturitas 77: 229-238, 2014.

14. Baysal BE, Ferrell RE, Willett-Brozick JE, Lawrence EC, Myssiorek D, Bosch A, van der Mey A, Taschner PE, Rubinstein WS, Myers EN, et al: Mutations in SDHD, a mitochondrial complex II gene, in hereditary paraganglioma. Science 287: 848-851, 2000.

15. Niemann S and Müller U: Mutations in SDHC cause autosomal dominant paraganglioma, type 3. Nat Genet 26: 268-270, 2000.

16. Astuti D, Latif F, Dallol A, Dahia PL, Douglas F, George E, Sköldberg F, Husebye ES, Eng C and Maher ER: Gene mutations in the succinate dehydrogenase subunit SDHB cause susceptibility to familial pheochromocytoma and to familial paraganglioma. Am J Hum Genet 69: 49-54, 2001.

17. Karasek D, Shah U, Frysak Z, Stratakis C and Pacak K: An update on the genetics of pheochromocytoma. J Hum Hypertens 27: 141-147, 2013.

18. Brouwers FM, Eisenhofer G, Tao JJ, Kant JA, Adams KT, Linehan WM and Pacak K: High frequency of SDHB germline mutations in patients with malignant catecholamine-producing paragangliomas: Implications for genetic testing. J Clin Endocrinol Metab 91: 4505-4509, 2006.

19. Fishbein L, Leshchiner I, Walter V, Danilova L, Robertson AG Johnson AR, Lichtenberg TM, Murray BA, Ghayee HK, Else T, Ling S, et al: Comprehensive molecular characterization of pheochromocytoma and paraganglioma. Cancer Cell 31: 181-193, 2017.

20. NGS, in PPGL (NGSnPPGL) Study Group; Toledo RA, Burnichon N, Cascon A, Benn DE, Bayley JP, Welander J, Tops CM, Firth H, Dwight T, et al: Consensus statement on next-generation-sequencing-based diagnostic testing of hereditary phaeochromocytomas and paragangliomas. Nat Rey Endocrinol 13: 233-247, 2017.

21. Zelinka T and Widimský J: Pheochromocytoma-why is its early diagnosis so important for patient? Vnitr Lek 61: 487-491, 2015.

22. Pacak K, Linehan WM, Eisenhofer G, Walther MM and Goldstein DS: Recent advances in genetics, diagnosis, localization and treatment of pheochromocytoma. Ann Intern Med 134 315-329, 2001

23. Chen H, Sippel RS, O'Dorisio MS, Vinik AI, Lloyd RV and Pacak K; North American Neuroendocrine Tumor Society (NANETS): The North American neuroendocrine tumor society consensus guideline for the diagnosis and management of neuroendocrine tumors: Pheochromocytoma, paraganglioma and medullary thyroid cancer. Pancreas 39: 775-783, 2010

24. Lenders JW, Pacak K, Walther MM, Linehan WM, Mannelli M, Friberg P, Keiser HR, Goldstein DS and Eisenhofer G: Biochemical diagnosis of pheochromocytoma: Which test is best? JAMA 287: 1427-1434, 2002.

25. Eisenhofer G, Siegert G, Kotzerke J, Bornstein SR and Pacak K Current progress and future challenges in the biochemical diagnosis and treatment of pheochromocytomas and paragangliomas. Horm Metab Res 40: 329-337, 2008.

26. Eisenhofer G, Goldstein DS, Walther MM, Friberg P, Lenders JW, Keiser HR and Pacak K: Biochemical diagnosis of pheochromocytoma: How to distinguish true-from false-positive test results. J Clin Endocrinol Metab 88: 2656-2666, 2003.

27. Jacques AE, Sahdev A, Sandrasagara M, Goldstein R, Berney D, Rockall AG, Chew S and Reznek RH: Adrenal phaeochromocytoma: Correlation of MRI appearances with histology and function. Eur Radiol 18: 2885-2892, 2008.

28. Motta-Ramirez GA, Remer EM, Herts BR, Gill IS and Hamrahian AH: Comparison of CT Findings in symptomatic and incidentally discovered pheochromocytomas. Am J Roentgenol 185: 684-688, 2005.

29. Čtvrtlík F, Heřman M, Študent V, Tichá V and Minařík J: Differential diagnosis of incidentally detected adrenal masses revealed on routine abdominal CT. Eur J Radiol 69: 243-252, 2009

30. Patel J,Davenport MS, Cohan RH and CaoiliEM: Can established $\mathrm{CT}$ attenuation and washout criteria for adrenal adenoma accurately exclude pheochromocytoma? AJR Am J Roentgenol 201: 122-127, 2013

31. Schieda N, Alrashed A, Flood TA, Samji K, Shabana W and McInnes MD: Comparison of quantitative MRI and CT washout analysis for differentiation of adrenal pheochromocytoma from adrenal adenoma. AJR Am J Roentgenol 206: 1141-1148, 2016.
32. Zhang GM, Shi B, Sun H, Jin ZY and Xue HD: Differentiating pheochromocytoma from lipid-poor adrenocortical adenoma by CT texture analysis: Feasibility study. Abdom Radiol 42: 2305-2313, 2017.

33. McDermott S, McCarthy CJ and Blake MA: Images of pheochromocytoma in adrenal glands. Gland Surg 4: 350-358, 2015.

34. Pacak K, Goldstein DS, Doppman JL, Shulkin BL, Udelsman R and Eisenhofer G: A 'pheo' lurks: Novel approaches for locating occult pheochromocytoma. J Clin Endocrinol Metab 86: 3641-3646, 2001.

35. Korobkin M, Giordano TJ, Brodeur FJ, Francis IR, Siegelman ES, Quint LE, Dunnick NR, Heiken JP and Wang HH: Adrenal adenomas: Relationship between histologic lipid and CT and MR findings. Radiology 200: 743-747, 1996.

36. Remer EM, Motta-Ramirez GA, Shepardson LB, Hamrahian AH and Herts BR: CT histogram analysis in pathologically proven adrenal masses. Am J Roentgenol 187: 191-196, 2006.

37. Lubner MG, Smith AD, Sandrasegaran K, Sahani DV and Pickhardt PJ: CT texture analysis: Definitions, applications, biologic correlates and challenges. RadioGraphics 37: 1483-1503, 2017.

38. Northcutt BG, Raman SP, Long C, Oshmyansky AR, Siegelman SS, Fishman EK and Johnson PT: MDCT of adrenal masses: Can dual-phase enhancement patterns be used to differentiate adenoma and pheochromocytoma? AJR Am J Roentgenol 201: 834-839, 2013.

39. Korobkin M, Brodeur FJ, Yutzy GG, Francis IR, Quint LE, Dunnick NR and Kazerooni EA: Differentiation of adrenal adenomas from nonadenomas using CT attenuation values. AJR Am J Roentgenol 166: 531-536, 1996.

40. Caoili EM, Korobkin M, Francis IR, Cohan RH and Dunnick NR: Delayed enhanced CT of lipid-poor adrenal adenomas. AJR Am J Roentgenol 175: 1411-1415, 2000.

41. Szolar DH, Korobkin M, Reittner P, Berghold A, Bauernhofer T, Trummer H, Schoellnast H, Preidler KW and Samonigg H: Adrenocortical carcinomas and adrenal pheochromocytomas: Mass and enhancement loss evaluation at delayed contrast-enhanced CT. Radiology 234: 479-485, 2005.

42. Kumagae Y, Fukukura Y, Takumi K, Shindo T, Tateyama A, Kamiyama T, Kamimura K and Nakajo M: Distinguishing adrenal adenomas from non-adenomas on dynamic enhanced CT: A comparison of 5 and 10 min delays afterintravenous contrast medium injection. Clin Radiol 68: 696-703, 2013.

43. Mukherjee JJ, Peppercorn PD, Reznek RH, Patel V, Kaltsas G, Besser M and Grossman AB: Pheochromocytoma: Effect of nonionic contrast medium in CT on circulating catecholamine levels. Radiology 202: 227-231, 1997.

44. Bessell-Browne R and O'Malley ME: CT of pheochromocytoma and paraganglioma: Risk of adverse events with i.v. administration of nonionic contrast material. AJR Am J Roentgenol 188: 970-974, 2007.

45. Mansmann G, Lau J, Balk E, Rothberg M, Miyachi Y and Bornstein SR: The clinically inapparent adrenal mass: Update in diagnosis and management. Endocr Rev 25: 309-340, 2004.

46. Tsushima Y, Takahashi-Taketomi A and Endo K: Diagnostic utility of diffusion-weighted MR imaging and apparent diffusion coefficient value for the diagnosis of adrenal tumors. J Magn Reson Imaging 29: 112-117, 2009.

47. Umanodan T, Fukukura Y, Kumagae Y, Shindo T, Nakajo M, Takumi K, Nakajo M,Hakamada H,Umanodan A and Yoshiura T: ADC histogram analysis for adrenal tumor histogram analysis of apparent diffusion coefficient in differentiating adrenal adenoma from pheochromocytoma. J Magn Reson Imaging 45: 1195-1203, 2017.

48. Dong Y and Liu Q: Differentiation of malignant from benign pheochromocytomas with diffusion-weighted and dynamic contrast-enhanced magnetic resonance at 3.0 T. J Comput Assist Tomogr 36: 361-366, 2012.

49. Kim S, Salibi N, Hardie AD, Xu J, Lim RP, Lee VS and Taouli B: Characterization of adrenal pheochromocytoma using respiratorytriggered proton MR spectroscopy: Initial experience. AJR Am J Roentgenol 192: 450-454, 2009.

50. Melo HJ, Goldman SM, Szejnfeld J, Faria JF, Huayllas MK, Andreoni C and Kater CE: Application of a protocol for magnetic resonance spectroscopy of adrenal glands: An experiment with over 100 cases. Radiol Bras 47: 333-341, 2014.

51. Reimer P, Parizel PM and Stichnoth FA: Clinical MR imaging: A practical approach Second, completely revised and updated (eds). Springer-Verlag, Berlin Heidelberg New York, 2006. 
52. Shellock FG and Kanal E: Safety of magnetic resonance imaging contrast agents. J Magn Reson Imaging 10: 477-484, 1999.

53. Taïeb D, Timmers HJ, Hindié E, Guillet BA, Neumann HP Walz MK, Opocher G, de Herder WW, Boedeker CC and de Krijger RR: EANM 2012 guidelines for radionuclide imaging of phaeochromocytoma and paraganglioma. Eur J Nucl Med Mol Imaging 39: 1977-1995, 2012.

54. Bombardieri E, Giammarile F, Aktolun C, Baum RP, Bischof Delaloye A, Maffioli L, Moncayo R, Mortelmans L, Pepe G, Reske SN, et al: 131I/123I-metaiodobenzylguanidine (mIBG) scintigraphy: Procedure guidelines for tumour imaging. Eur J Nucl Med Mol Imaging 37: 2436-2446, 2010.

55. Treglia G, Cocciolillo F, de Waure C, Di Nardo F, Gualano MR, Castaldi P, Rufini V and Giordano A: Diagnostic performance of $18 \mathrm{~F}$-dihydroxyphenylalanine positron emission tomography in patients with paraganglioma: A meta-analysis. Eur J Nucl Med Mol Imaging 39: 1144-1153, 2012.

56. Fiebrich HB, Brouwers AH, Kerstens MN, Pijl ME, Kema IP, de Jong JR, Jager PL, Elsinga PH, Dierckx RA, van der Wal JE, et al: 6-(F-18)Fluoro-1-dihydroxyphenylalanine positron emission tomography is superior to conventional imaging with 123I-metaiodobenzylguanidine scintigraphy, computer tomography and magnetic resonance imaging in localizing tumors causing catecholamine excess. J Clin Endocrinol Metab 94: 3922-3930, 2009.

57. Timmers HJ, Chen CC, Carrasquillo JA, Whatley M, Ling A, Eisenhofer G, King KS, Rao JU, Wesley RA, Adams KT and Pacak K: Staging and functional characterization of pheochromocytoma and paraganglioma by $18 \mathrm{~F}$-fluorodeoxyglucose $\left({ }^{18} \mathrm{~F}-\mathrm{FDG}\right)$ positron emission tomography. J Natl Cancer Inst 104: 700-708, 2012.

58. Janssen I, Chen CC, Millo CM, Ling A, Taieb D, Lin FI, Adams KT, Wolf KI, Herscovitch P, Fojo AT, et al: PET/CT comparing (68)Ga-DOTATATE and other radiopharmaceuticals and in comparison with CT/MRI for the localization of sporadic metastatic pheochromocytoma and paraganglioma. Eur J Nucl Med Mol Imaging 43: 1784-1791, 2016.

59. Jing H, Li F, Wang L, Wang Z, Li W, Huo L and Zhang J: Comparison of the 68Ga-DOTATATA PET/CT, FDG PET/CT and MIBG SPECT/CT in the evaluation of suspected primary pheochromocytomas and paragangliomas. Clin Nucl Med 42: 525-529, 2017

60. Chang CA, Pattison DA, Tothill RW, Kong G, Akhurst TJ, Hicks RJ and Hofman MS: 68Ga-DOTATATE and ${ }^{18} \mathrm{~F}-\mathrm{FDG}$ $\mathrm{PET} / \mathrm{CT}$ in paraganglioma and pheochromocytoma: Utility, patterns and heterogeneity. Cancer Imaging 16, 2016.

61. Tato A, Orte L, Diz P, Quereda C and Ortuno J: Malignant pheochromocytoma, still a therapeutic challenge. Am J Hypertens 10: 479-481, 1997.
62. Strong VE, Kennedy T, Al-Ahmadie H, Tang L, Coleman J, Fong Y, Brennan M and Ghossein RA: Prognostic indicators of malignancy in adrenal pheochromocytomas: Clinical, histopathologic and cell cycle/apoptosis gene expression analysis. Surgery 143: 759-768, 2008.

63. Thompson LD: Pheochromocytoma of the adrenal gland scaled score (PASS) to separate benign from malignant neoplasms: A clinicopathologic and immunophenotypic study of 100 cases. Am J Surg Pathol 26: 551-566, 2002.

64. Mlika M, Kourda N, Zorgati MM, Bahri S, Ben Ammar S and Zermani R: Prognostic value of Pheochromocytoma of the adrenal gland scaled score (Pass score) tests to separate benign from malignant neoplasms. Tunis Med 91: 209-215, 2013.

65. de Wailly P, Oragano L, Radé F, Beaulieu A, Arnault V, Levillain P and Kraimps JL: Malignant pheochromocytoma: New malignancy criteria. Langenbecks Arch Surg 397: 239-246, 2012.

66. Duregon E, Volante M, Bollito E, Goia M, Buttigliero C, Zaggia B, Berruti A, Scagliotti GV and Papotti M: Pitfalls in the diagnosis of adrenocortical tumors: A lesson from 300 consultation cases. Hum Pathol 46: 1799-1807, 2015.

67. Ctvrtlik F, Koranda P and Tichy T: Adrenal disease: A clinical update and overview of imaging. Biomed Pap Med Fac Univ Palacky Olomouc Czech Repub 158: 23-34, 2014.

68. Hodin R, Lubitz C, Phitayakorn R and Stephen A: Diagnosis and management of pheochromocytoma. Curr Probl Surg 51: 151-187, 2014.

69. Vanderveen KA, Thompson SM, Callstrom MR, Young WF Jr, Grant CS, Farley DR, Richards ML and Thompson GB: Biopsy of pheochromocytomas and paragangliomas: Potential for disaster. Surgery 146: 1158-1166, 2009.

70. Brunaud L, Nguyen-Thi PL, Mirallie E, Raffaelli M, Vriens M, Theveniaud PE, Boutami M, Finnerty BM, Vorselaars WM, Rinkes IB, et al: Predictive factors for postoperative morbidity after laparoscopic adrenalectomy for pheochromocytoma: A multicenter retrospective analysis in 225 patients. Surg Endosc 30: 1051-1059, 2015.

71. Perel Y, Schlumberger M, Marguerite G, Alos N, Revillon Y, Sommelet D, De Lumley L, Flamant F, Dyon JF, Lutz P, et al: Pheochromocytoma and paraganglioma in children: A report of 24 cases of the french society of pediatric oncology. Pediatr Hematol Oncol 14: 413-422, 1997.

72. Wang W, Li P, Wang Y, Wang Y, Ma Z, Wang G, Gao J and Zhou H: Effectiveness and safety of laparoscopic adrenalectomy of large pheochromocytoma: A prospective, nonrandomized, controlled study. Am J Surg 210: 230-235, 2015.

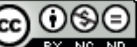

This work is licensed under a Creative Commons

Attribution-NonCommercial-NoDerivatives 4.0 International (CC BY-NC-ND 4.0) License. 